Bond University

Research Repository

\title{
Physical therapist postprofessional education in the United States and Australia
}

Westervelt, Karen; Crane, Linda H; Sibold, Jeremy; Hing, Wayne A

Published in:

Physical Therapy Reviews

DOI:

10.1080/10833196.2017.1336839

\section{Licence:}

Unspecified

Link to output in Bond University research repository.

Recommended citation(APA):

Westervelt, K., Crane, L. H., Sibold, J., \& Hing, W. A. (2018). Physical therapist postprofessional education in the United States and Australia. Physical Therapy Reviews, 23(1), 68-76.

https://doi.org/10.1080/10833196.2017.1336839

\section{General rights}

Copyright and moral rights for the publications made accessible in the public portal are retained by the authors and/or other copyright owners and it is a condition of accessing publications that users recognise and abide by the legal requirements associated with these rights.

For more information, or if you believe that this document breaches copyright, please contact the Bond University research repository coordinator. 


\title{
Physical Therapist Postprofessional Education in the United States and Australia
}

\begin{abstract}
Background: In line with policy recommendations from the World Confederation of Physical Therapy, Australia (AUS) and the United States (USA) actively promote postprofessional physical therapist education. Although postprofessional education pathways vary, the goal of educating specialists within the profession is shared.

Objectives: In order to advance education, and ultimately the profession, it is necessary to understand what is offered for postprofessional programs. Therefore, this study aimed to investigate and compare physical therapist postprofessional education in two regions of the world.
\end{abstract}

Methods: Data were collected from relevant professional organizations, electronic media, and academic programs. Descriptive statistics were generated to compare postprofessional programs in AUS and USA.

Major Findings: Variation was demonstrated in postprofessional education between both countries. Notably, the number of programs was observed to be growing in the USA, but declining in AUS, where six programs closed during data collection. AUS offered 41 postprofessional programs, while the USA offered 242 residency, and 49 fellowship, programs. USA and AUS had the most programs in musculoskeletal / sports, $42.6 \%$ and $24.4 \%$ respectively. Conversely, geriatrics comprised only $7.4 \%$ of USA residence programs and $0 \%$ of AUS clinical academic programs.

Conclusion: This research compared postprofessional education in AUS and USA and demonstrated universal issues related to accessibility and programming. The declining number of programs in AUS is of great concern and warrants evaluation of postprofessional education 
globally. Educators need to ensure that postprofessional education is accessible, innovative, meets the population needs. This research demonstrates opportunities for international collaboration within the physical therapy profession to advance education and ultimately the profession.

Keywords: physical therapist, physiotherapist, postprofessional education, specialization, internationalization 


\section{Introduction:}

In line with policy recommendations from the World Confederation of Physical Therapy (WCPT), ${ }^{1}$ Australia (AUS) and the United States (USA) promote postprofessional physical therapist (PT) education. ${ }^{2-5}$ The pathways of postprofessional education vary globally; however, the goal of generating a group of clinical experts within the profession that have advanced knowledge and skills is shared. Postprofessional education programs transform general practitioners into specialists who often lead advances in PT education and research. ${ }^{6}$

Postprofessional PT education is in a state of rapid change; therefore, in order to promote advances in postprofessional PT education, and ultimately the profession, we first need to understand what is offered for postprofessional programs in different countries. Understanding PT education globally and collaborating with international partners on educational issues is essential in order to progress the profession in education, research, and clinical practice. ${ }^{7}$ Therefore, the aim of this research was to investigate postprofessional PT education in two comparative regions of the world.

\section{Postprofessional education in AUS}

Australia recognized its first specialist physiotherapist (PT) in $1983 .{ }^{3,8}$ Currently, there is a 3 tier system to reach Specialist in AUS that is offered and promoted by the Australian Physiotherapy Association (APA) and the Australian College of Physiotherapy (ACP) and requires membership in the APA. In 2016, approximately $76 \%$ of registered PTs in Australia were members of the APA. ${ }^{9,10}$ Tier 1 is attained by graduating from an accredited entry level program and Tier 2, by becoming a Titled Member of the APA. Tier 3 is to become a Specialist and a Fellow of the ACP. A PT desiring to become Titled must choose between 2 primary pathways: 1) an academic pathway, which involves completion of an APA approved master's 
course and at least 2 years clinical experience, or 2) the experiential pathway, which involves at least 5 years of clinical practice, with 3 of those years in the area of interest, 20 hours of continuing professional development in the area of interest within the year prior to sitting the exams, and passing of a written exam and a practical exam. The PT can then elect for more education to attain Tier 3 and become a 'Specialist Physiotherapist' and a Fellow of the ACP. This involves 2 additional years of training facilitated by a Fellow of the ACP, followed by passing of an oral and practical exam. ${ }^{11}$

Career pathways towards specialization are promoted by the APA and specialization is awarded by the ACP. ${ }^{12}$ Today, AUS recognizes 8 areas of specialization including: cardiorespiratory, continence \& women's health, gerontology, musculoskeletal, neurology, occupational health, pediatrics, and sports. ${ }^{12}$ In 2017, there were 148 Specialist Physiotherapists in AUS. ${ }^{13}$ Postprofessional education is offered in AUS in the form of postgraduate certificates, postgraduate diplomas, master's degrees, and Doctor of Philosophy programs. Fellowships are also available, but they are designed and established individually, and coordinated through the ACP. All of these programs strive to provide high quality education in order to meet the work force need for more PT specialists. ${ }^{14}$ Despite Australia's international reputation as a leader in postprofessional PT education there has been a decline in the number of Australian's attending these programs 'potentially compromising the ongoing development and advancement of the profession. ${ }^{.15(\mathrm{p} 75)}$

\section{Postprofessional education in USA}

The USA recognized its first specialist in $1985 .{ }^{16}$ The term 'Specialist' in the USA is not awarded at the Fellow level as it is in AUS, but can be equated to the AUS Titled level. There are 2 routes to becoming a certified clinical specialist in the USA: 1) the residency route, which 
involves completion of a 12-18 month accredited clinical residency within the specialty area followed by a written examination and 2) the experiential route which involves 2000 hours of patient care in the specialty area followed by a written examination. ${ }^{17}$ An individual interested in further education can then go onto a narrower focus of study in a fellowship program.

The ABPTS recognizes 8 areas of specialization: cardiovascular and pulmonary, clinical electrophysiology, geriatrics, neurology, orthopaedics, pediatrics, sports, and women's health. American Board of Physical Therapy Residency and Fellowship Education (ABPTRFE) is responsible for accrediting residency and fellowship programs. ${ }^{18}$ As of June 2016 there were 20,144 Board Certified Clinical Specialists in the USA. ${ }^{19}$ For the past several years there have been more qualified applicants than spaces in residency and fellowship programs. This has caused a surge in the number of developing programs in an attempt to meet the growing demand (Kendra L. Harrington, PT, DPT, MS, WSC; email communication March 24, 2015 and July 26, 2016) and has resulted in the USA being at a "critical period" in residency and fellowship education. $^{20(p 950)}$

\section{Objectives}

According to Cahalin et al in 2008, 'A better understanding of worldwide physical therapy educational and professional issues may strengthen physical therapy practice, education, and research around the globe'..$^{7\left(\mathrm{p}^{34)}\right)}$ Due to the lack of published information in this area, this research was undertaken to collate information on available postprofessional programs in USA and AUS and to establish a comparative analysis. Therefore, the objectives of this research project were: (1) to identify the number of postprofessional education programs in both the USA and AUS; (2) to identify the location of postprofessional education programs in both the USA and AUS; (3) to identify the specialty areas of postprofessional education programs in both the 
USA and AUS; (4) to examine trends in postprofessional PT education in 2 different regions of the world; (5) to advocate for international collaboration and dialogue to promote postprofessional PT education and advances within the profession globally.

\section{Methods}

The research design is a historical descriptive study utilizing quantitative methods. ${ }^{21}$ AUS and USA were selected to study because both countries: promote the WCPT Education Policy for postprofessional education, ${ }^{1}$ have high-quality of entry-level education, have a large number of PTs (30,004 registered in $\mathrm{AUS}^{10}$ and 202,444 licensed in the USA as of Dec 2016 ${ }^{22}$ ), have postprofessional continuing education requirements, are considered among the forerunners in postprofessional PT education, ${ }^{2,4}$ and are English speaking.

\section{Data collection}

Information on postprofessional programs in AUS provided by the Queensland Government in collaboration with Council of Physiotherapy Deans Australia and New Zealand (CPDANZ) was examined. ${ }^{23}$ Information was current as of August 13, 2015. This information was then confirmed and/or updated via email communication with all the relevant Australian universities. Information was updated as of February 2, 2016. Program specialty was categorized based on provided information from the aforementioned sources. Location of program was reported for the main campus of program.

Similarly, data were first collected on residency and fellowship programs in the USA from the ABPTRFE directory of programs found on the ABPTRFE webpage. ${ }^{24}$ Data were collected from each program's profile. If the data was incomplete, the listed program director was emailed to verify questionable data or provide information to complete the data set.

\section{Data Analysis}


Data were entered into an Excel spreadsheet (Microsoft Excel; 2013) and analyzed through the GMAP procedure of SAS/Graph software (version 9.4) part of the SAS System for Windows (SAS Institute 2010, Cary, NC). Maps were generated of both the USA and AUS to represent the different levels of education each country offered. Programs were plotted based on their county ID code in the USA or city code for AUS. A key code was created to account for program specialty. Program specialty was categorized based on provided information from source. Descriptive statistics were then calculated and comparative analysis completed.

\section{Major Findings}

\section{Postprofessional Programs AUS}

As of March 2016, there were 41 postprofessional degree programs offered in AUS. The degrees offered include clinical master's, graduate certificates and graduate diplomas. Fellowships, research master's and $\mathrm{PhD}$ programs were excluded from this research since these do not have comparable pathways specialization in the USA. Clinical academic program areas identified included: musculoskeletal/sports, neurology/rehabilitation, clinical education, women's health, burn and trauma, pediatrics and other, with 'other' consisting of rural health practice, international primary healthcare practice, and advanced clinical practice. Figure 1 displays the location of these 41 programs as well as the area of study. Lists of these programs by location are displayed in Table 1. Within the six months of data collection, five master's programs and one short course closed. 
Figure 1. AUS Postprofessional Education Programs

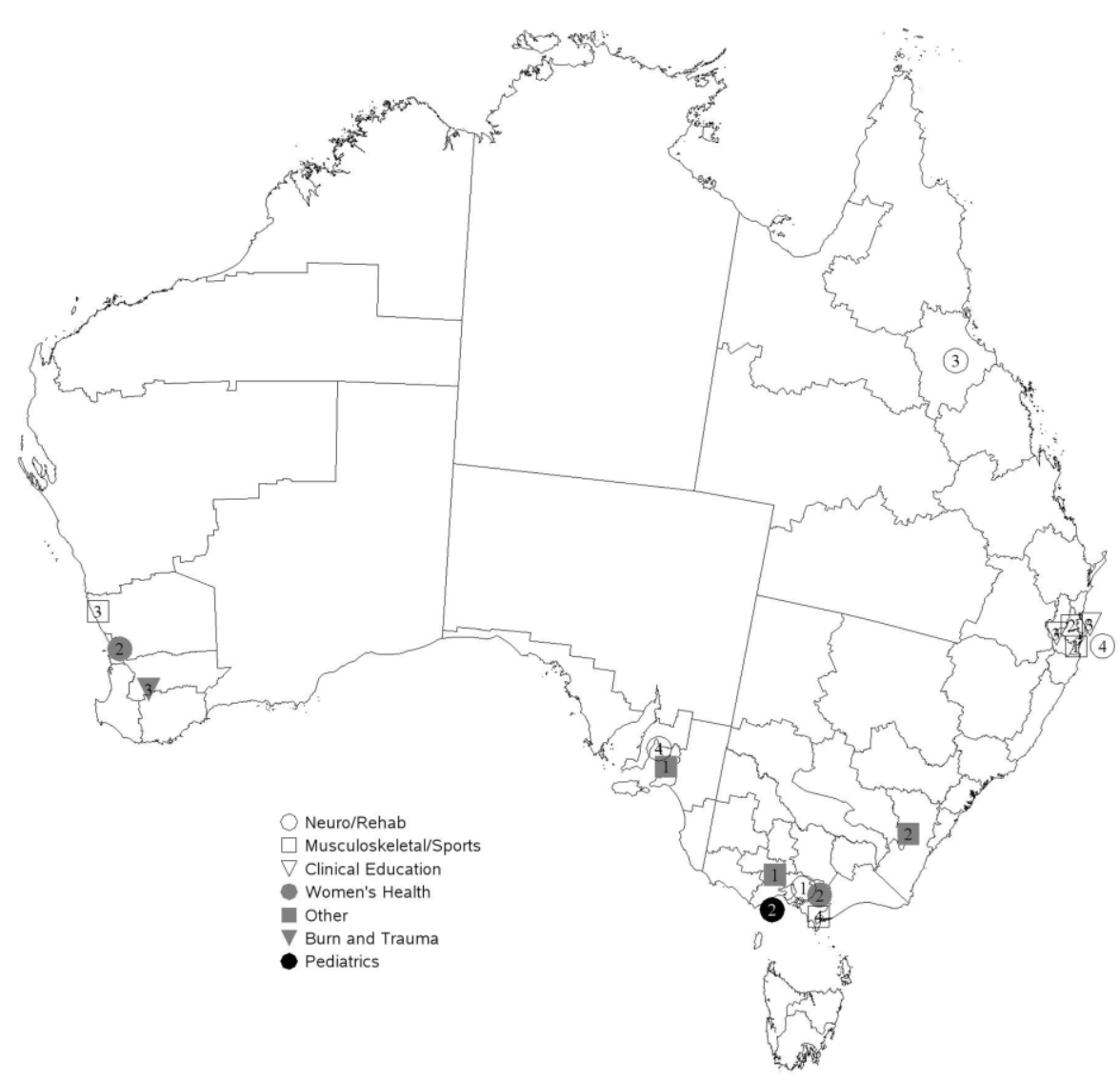

Table 1. AUS Postprofessional Programs

\begin{tabular}{|c|c|c|c|c|c|c|c|c|c|c|}
\hline City & $\begin{array}{c}\text { Mskl/ } \\
\text { Sports* }\end{array}$ & $\begin{array}{l}\text { Neuro/ } \\
\text { Rehab* }\end{array}$ & $\begin{array}{c}\text { Pediatr } \\
\text { ics* }\end{array}$ & $\begin{array}{l}\text { Women's } \\
\text { Health* }\end{array}$ & Gerontology* & $\begin{array}{c}\text { Occupatio } \\
\text { nal } \\
\text { Health* }\end{array}$ & $\begin{array}{c}\text { Cardio/ } \\
\text { pulmonary } \\
*\end{array}$ & $\begin{array}{l}\text { Burn \& } \\
\text { Trauma }\end{array}$ & $\begin{array}{c}\text { Clinical } \\
\text { Education }\end{array}$ & Other \\
\hline Adelaide & & 1 & & & & & & & & 4 \\
\hline Brisbane & 2 & 4 & & & & & & & 3 & \\
\hline Canberra & & & & & & & & & & 2 \\
\hline Gold Coast & 1 & & & & & & & & 3 & \\
\hline Melbourne & 4 & 1 & 2 & 2 & & & & & & 1 \\
\hline Townsville & & 3 & & & & & & & & \\
\hline Perth & 3 & & & 2 & & & & 3 & & \\
\hline Total & 10 & 9 & 2 & 4 & 0 & $\mathbf{0}$ & $\mathbf{0}$ & 3 & 6 & 7 \\
\hline
\end{tabular}

*Represents areas of specialization promoted by the APA 
Of the 41 postprofessional education programs available in AUS, 48.8\% (20/41) of the programs are at the Master's degree level. Graduate Certificate programs represent $34.1 \%$ $(14 / 41)$ of programs. Graduate Diplomas represent $17.1 \%(7 / 41)$ of programs.

The most prevalent area of study offered is musculoskeletal/sports at $24.4 \%(10 / 41)$. The second most prevalent area of study is neurology/rehabilitation representing $22 \%(9 / 41)$. The remaining programs listed by descending order of prevalence include 'other' at 7/41, clinical education with 6/41, burn and trauma and women's health each with 3/41 programs, and pediatrics with 2/41 programs.

Seven different cities (Adelaide, Brisbane, Canberra, Gold Coast, Melbourne, Townville, and Perth) located in 5 of the federated states were mapped out to display the location of programs offered in Figure 1. The majority of programs can be found in Melbourne which represents $24.4 \%(10 / 41)$ of programs. Brisbane offers $22 \%(9 / 41)$ of programs and Perth offers $19.5 \%(8 / 41)$ of programs. The remaining four cities offer a range of 5 to 2 programs: Adelaide (5/41), Gold Coast (4/41), Townsville (3/41) and Canberra (2/41). There are no programs in the 2 mainland territories or in the State of Tasmania.

\section{Postprofessional Residency Programs in the USA}

Postprofessional programs in the USA include residencies and fellowships. PhD programs were again excluded. As of November 2015, there were 242 residency programs in the United States. Residency programs were offered in 10 areas of specialization: acute care, cardiopulmonology, clinical electrophysiology, geriatrics, neurology, orthopaedics, pediatrics, sports, women's health and wound care. Figure 2 displays the location of each residency program by county and the type of program offered. The programs are listed by location/state in Table 2. The distribution of specialization areas for residences can be seen in Table 3. 
Table 2. USA Residency Programs

\begin{tabular}{|c|c|c|c|c|c|c|c|c|c|c|}
\hline State & $\begin{array}{c}\text { Acute } \\
\text { Care }\end{array}$ & $\begin{array}{l}\text { Cardio- } \\
\text { pulm* }\end{array}$ & $\begin{array}{l}\text { Clinical } \\
\text { Electro* }\end{array}$ & Geriatrics* & Neurology* & Orthopaedics* & Pediatrics* & Sports* & $\begin{array}{l}\text { Women's } \\
\text { Health* }\end{array}$ & $\begin{array}{c}\text { Wound } \\
\text { Care }\end{array}$ \\
\hline AR & & & & & & & 1 & & & \\
\hline $\mathbf{A Z}$ & & & & 1 & 2 & 4 & & 1 & & \\
\hline $\mathbf{C A}$ & & & & 1 & 6 & 15 & 1 & 2 & & \\
\hline $\mathrm{CO}$ & & & & & & 2 & 1 & & & \\
\hline CT & & & & 2 & & 1 & & & & \\
\hline DC & & & & & & & & 1 & 1 & \\
\hline DE & & & & 1 & & 2 & & 2 & & \\
\hline FL & & & & 3 & 3 & 7 & 2 & 2 & 1 & \\
\hline GA & & 1 & & & 2 & 5 & 1 & 1 & & \\
\hline IA & & & & & & 1 & & & & \\
\hline ID & & & & & & & & 1 & & \\
\hline IL & & & & & & 6 & 1 & & 1 & \\
\hline IN & & & & & & 1 & & 1 & & \\
\hline KY & & & & & 2 & 2 & & 1 & & \\
\hline LA & & & & & 1 & 2 & & & & 1 \\
\hline MA & & 1 & & & 1 & 1 & 1 & 1 & 1 & \\
\hline MD & 1 & & & & 1 & 2 & 2 & 1 & & \\
\hline MI & & 1 & & & 1 & 3 & 1 & & & \\
\hline MN & & & & 1 & & 2 & & & 1 & \\
\hline MO & & & & & & 1 & & & 1 & \\
\hline MS & & & & & 1 & & & 1 & & \\
\hline NC & & 1 & & 1 & & 3 & 2 & 1 & 1 & \\
\hline ND & & & & & & 1 & & 1 & & \\
\hline NE & & & & 1 & 1 & 1 & 2 & & & \\
\hline NJ & & & & 1 & 1 & & & & & \\
\hline NY & & & & & 2 & 5 & & 2 & & \\
\hline OH & & & & 3 & 1 & 6 & 3 & 4 & & \\
\hline OR & & & & & & 2 & 1 & & & \\
\hline PA & & & 1 & 1 & 3 & 9 & 2 & 3 & 2 & \\
\hline SC & & & & & 1 & 2 & & 1 & & \\
\hline TN & & & & 1 & 3 & 3 & 1 & 3 & 1 & \\
\hline TX & & & & 1 & 3 & 4 & 6 & & & \\
\hline UT & & & & & 1 & 1 & & & & \\
\hline VA & & & & & 1 & 2 & & 3 & & \\
\hline WA & & & & & 1 & 4 & & 1 & & \\
\hline WI & & 1 & & & 1 & 3 & 2 & & & \\
\hline Total & 1 & 5 & 1 & 18 & 39 & 103 & 30 & 34 & 10 & 1 \\
\hline
\end{tabular}

Table 3. USA Residencies by Area of Specialization 


\begin{tabular}{ll}
\hline Orthopaedics & $42.6 \%(103 / 242)$ \\
\hline Neurology & $16.1 \%(39 / 242)$ \\
\hline Sports & $14.0 \%(34 / 242)$ \\
\hline Pediatrics & $12.4 \%(30 / 242)$ \\
\hline Geriatrics & $7.4 \%(18 / 242)$ \\
\hline Women's Health & $4.1 \%(10 / 242)$ \\
\hline Cardopulmonology & $2.0 \%(5 / 242)$ \\
\hline Acute Care & $.04 \%(1 / 242)$ \\
\hline Clinical Electrophysiology & $.04 \%(1 / 242)$ \\
\hline Wound Care & $.04 \%(1 / 242)$ \\
\hline
\end{tabular}

Figure 2 shows the distributions of residencies by locations/states. Five states had $42.1 \%$ (102/242) of the residency programs. These states were California (25), Pennsylvania (22), Texas (19), Florida (19) and Ohio (17). There were 17 states without a program. 
Figure 2. USA Residencies.

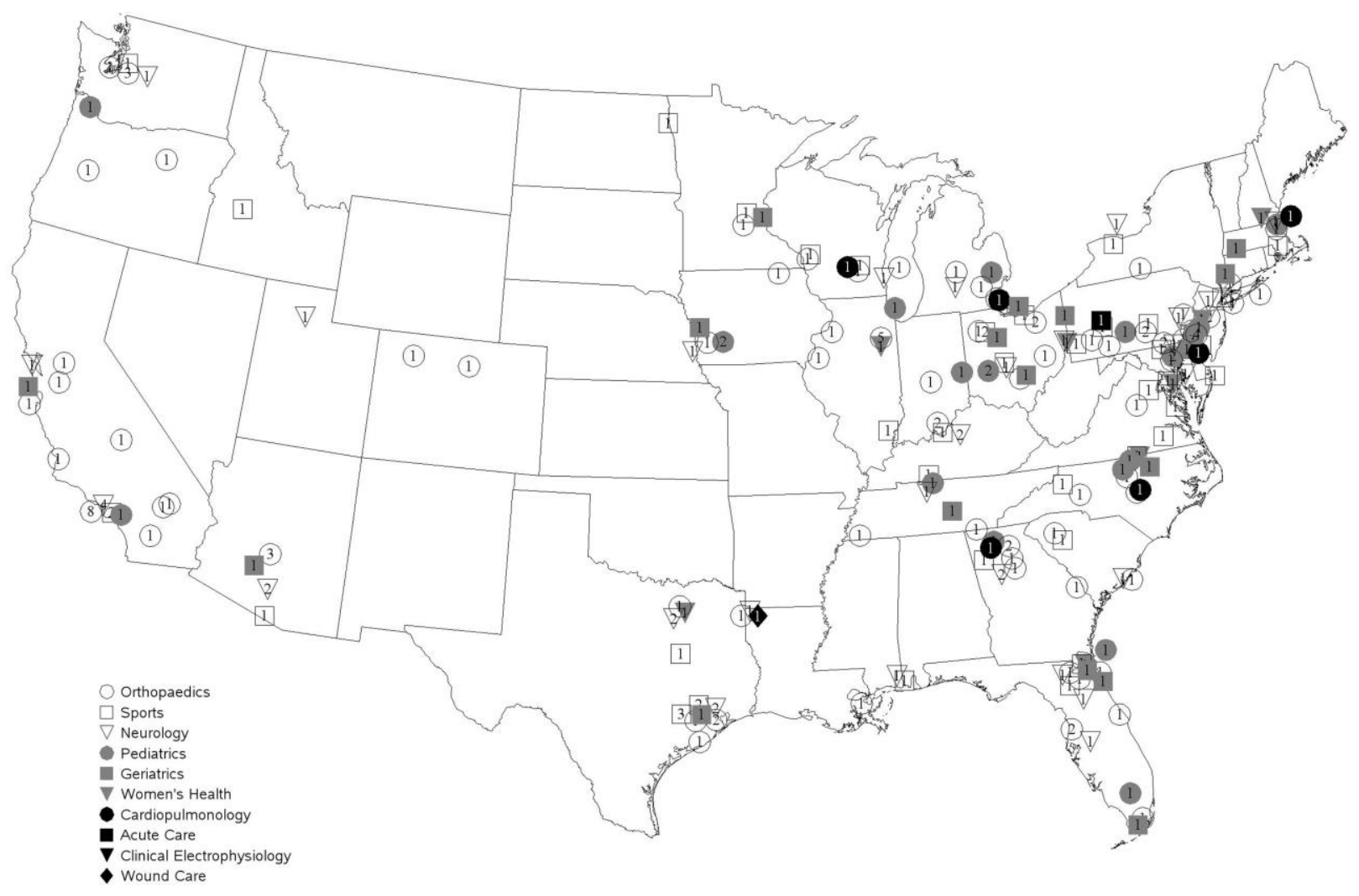

\section{Postprofessional Fellowship Programs in the USA}

As of November 2015, there were 49 fellowship programs in the United States.

Fellowship programs in Orthopaedic Manual Physical Therapy account for the majority of the programs at (30/49) $61.2 \%$ of total fellowship programs available. The following fellowships were also available in the order of prevalence: Spine (4/49), Critical Care (3/49), Sports Division I (3/49), Upper Extremity Athlete (3/49), Neonatology (2/49), Hand Therapy (2/49), Education Leadership (1/49), and Movement Science (1/49). The location of the 49 fellowships by county and specialization are shown in Figure 3. This information is listed by state in Table 4. 
Figure 3. USA Fellowships.

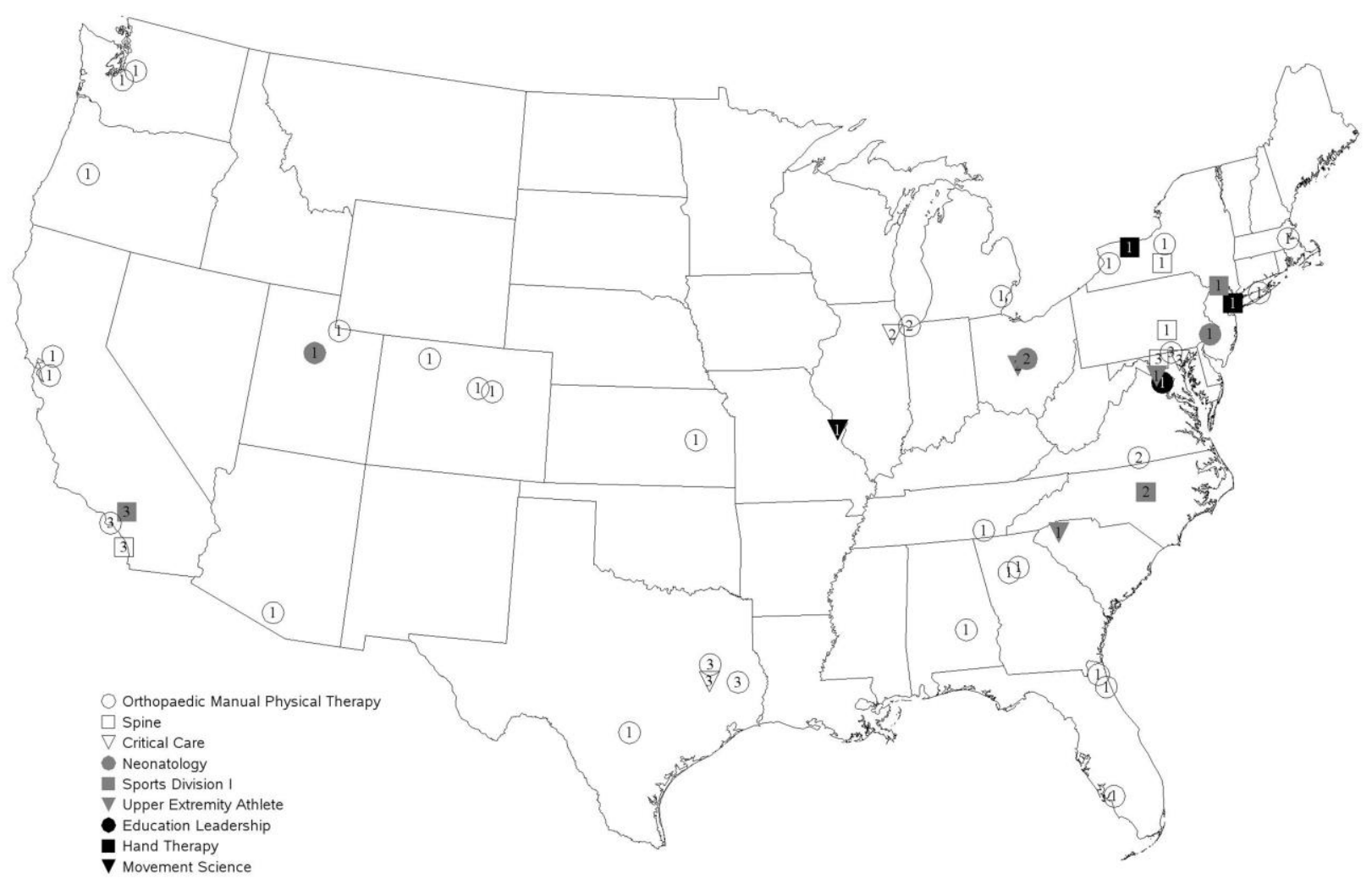


Table 4. USA Fellowship Programs

\begin{tabular}{|c|c|c|c|c|c|c|c|c|c|}
\hline State & $\begin{array}{l}\text { Critical } \\
\text { Care }\end{array}$ & $\begin{array}{c}\text { Education } \\
\text { Leadership }\end{array}$ & $\begin{array}{c}\text { Hand } \\
\text { Therapy }\end{array}$ & $\begin{array}{c}\text { Movement } \\
\text { Science }\end{array}$ & Neonatology & $\begin{array}{c}\text { Orthopaedic } \\
\text { Manual Therapy }\end{array}$ & Spine & $\begin{array}{c}\text { Sports } \\
\text { Division I }\end{array}$ & $\begin{array}{c}\text { Upper } \\
\text { Extremity } \\
\text { Athlete }\end{array}$ \\
\hline $\mathbf{A L}$ & & & & & & 1 & & & \\
\hline $\mathbf{A Z}$ & & & & & & 1 & & & \\
\hline CA & & & & & & 3 & 1 & 1 & \\
\hline $\mathrm{CO}$ & & & & & & 3 & & & \\
\hline FL & & & & & & 3 & & & \\
\hline GA & & & & & & 1 & & & \\
\hline IL & 1 & & & & & 1 & & & \\
\hline KY & & & & & & 1 & & & \\
\hline MA & & & & & & 1 & & & \\
\hline MD & 1 & & & & & 2 & 1 & & \\
\hline MI & & & & & & 1 & & & \\
\hline MO & & & & 1 & & & & & \\
\hline $\mathrm{NC}$ & & & & & & 1 & & 1 & \\
\hline NY & & & 2 & & & 3 & 1 & 1 & \\
\hline $\mathbf{O H}$ & & & & & 1 & & & & 1 \\
\hline OR & & & & & & 1 & & & \\
\hline PA & & & & & & & 1 & & \\
\hline SC & & & & & & & & & 1 \\
\hline TN & & & & & & 1 & & & \\
\hline TX & 1 & & & & & 3 & & & \\
\hline UT & & & & & 1 & 1 & & & \\
\hline VA & & 1 & & & & & & & 1 \\
\hline WA & & & & & & 2 & & & \\
\hline Total & 3 & 1 & 2 & 1 & 2 & 30 & 4 & 3 & 3 \\
\hline
\end{tabular}

Only 23 states had fellowship programs. $30.6 \%$ of all programs offered could be found in just 3 states. New York offered 6, California offered 5 and Texas offered 4 fellowship programs. More than half the states in the USA, 28 states, did not offer a fellowship program.

\section{Conclusion}

\section{Discussion}

This research collated and compared information about postprofessional programs within AUS and USA, and demonstrated opportunities for learning and areas of similarity and disparity. Similarities in AUS \& USA Postprofessional Education

Both countries shared challenges related to access to education geographically. In AUS, 39 of the 41 postprofessional programs offered an online component, thereby improving access. However, the programs often required travel and short stays to the academic center for face-to- 
face educational programming. In the USA the issue of access is accentuated by the format of fellowships, which require clinical mentoring by a Fellow, and residencies, which require clinical work, didactic work and mentoring by a Clinical Specialist. ${ }^{25}$ A recent survey of PTs in AUS and USA reported that access, both geographically and financially, was a significant barrier for many clinicians wanting to pursue postprofessional education. ${ }^{26}$

Another similarity in both these regions was the area of study. There were a large number of orthopaedics/manual therapy and sports program in the USA and a large number of musculoskeletal/sport programs in AUS. The term 'orthopaedic' in the USA refers to musculoskeletal populations, and the musculoskeletal/sports specialization in AUS includes manual therapy. Therefore, once the terminology was clarified, the most common area of study in postprofessional programs was the same in both countries.

In addition to comparing the most common areas of programming, this research also identified areas of need. For example, the growing geriatric population and the relatively low number of geriatric residency programs in the USA, 7.4\% (18/242) programs, might suggest the need for more programs within this area. AUS recognizes gerontology as an area of specialization but offered no postprofessional clinically based academic programs in this area, likewise identifying an area of need for the aging Australian population. Similarly, although the leading cause of death in the USA and AUS is coronary heart disease, ${ }^{27,28}$ the USA only offered 5 residency programs in cardio-pulmonology, while AUS offers no clinical academic postprofessional programs in this area. These findings support the recommendations from experts for a broader distribution of residency programs into all specialty areas. ${ }^{29,30}$ Differences in AUS and USA Postprofessional Education 
The results demonstrated differences in postprofessional education between the 2 regions. The initial difference is in the use of the term 'specialist'. This term is reserved for the highest level of clinical training, the Fellow level, in AUS but is used below the Fellow level in the USA similar to the AUS Titled level. Variation in the use of the term 'specialist' from one country to another can create confusion within the profession and the public. Another difference was a disconnect between nationally recognized areas of specialization and academic programs that offer that area of study. In AUS, postprofessional academic programs were only offered in 5 of the 8 areas of specialization and in 5 other areas. Not having a program in 3 areas of specialization automatically limits the pathway to become Titled to only the experiential pathway. In the USA, residency and fellowship programs were available in all 8 specialty areas and in 2 additional areas of emerging interest. However, residency and fellowship programs in the USA are still considered in their infancy stage and are not necessarily offered in areas of greatest need for the population. ${ }^{20}$

Another area of difference was the degree earned in postprofessional education. Postprofessional education in AUS can be a progressive system in which a PT first earns a postgraduate certificate, then adds on course work to earn a postgraduate diploma, and finally completes an additional year of clinical and course work to earn a clinical master's degree. These programs are recognized by the APA for the purpose of Titling but not accredited by a single registration authority as they are in the USA. A benefit of this progressive system is the practicality for a busy clinician to gradually earn a higher qualification.

Postprofessional residency and fellowship programs in the USA are accredited by ABPTRF. Despite tremendous interest, committing to a residency program and then a fellowship 
program is a big financial and time commitment, and may be lacking the practicality of the articulated AUS system.

One of the biggest differences demonstrated was in numbers of programs. For the past decade there has been concern that the declining number of Australian PTs attending postprofessional programs will force programs to close, potentially compromising the advancement of the profession. ${ }^{15}$ These concerns appear to be legitimate as this research demonstrated a decline of postprofessional education programs in AUS. ${ }^{6}$ During the 6 months of data collection, 6 AUS postprofessional programs closed. This decline may be partially due to the lack of professional recognition of the importance of postprofessional education, lack of a tiered remuneration system for clinical specialists, the onerous pathway to become a specialist, and the rising cost of postprofessional education. , $^{6,15,31}$

Conversely, the USA has a rising number of clinical specialists and programs. ${ }^{32}$ The USA has established an organized and clear pathway towards specialization and is amassing a significant percentage of the PT workforce as specialists; however, similar to AUS it lacks appropriate recognition and financial compensation for trained specialists. When PTs from AUS and USA were surveyed about benefits of postprofessional education, PTs reported recognition and compensation were important benefits to deciding to pursue postprofessional education. ${ }^{26}$

Although AUS's postprofessional PT education started before the USA, AUS has a small number of specialists, making it difficult for the profession to win recognition and compensation for specialists. It is imperative to come up with novel solutions to reverse the current trend of declining postprofessional PT education in AUS. The USA has a larger and actively growing number of specialists, and will soon approach a critical mass who can advocate for better recognition and compensation. The USA could benefit from studying the AUS system and 
learning from their colleagues that if this recognition does not follow in a timely manner, interest in specialization training could wane. This would be a great loss for the profession locally and globally. A clear opportunity for internationalization and collaboration in postprofessional education currently exists.

\section{International Collaboration}

The WCPT describes postprofessional education as a vital component to physical therapy practice and development. ${ }^{33}$ As PTs continue to expand their roles, they must be prepared to practice in an increasingly interdependent world.$^{34}$ International collaborations among entry level students have been demonstrated to be beneficial to visitors, hosts and faculty ${ }^{35}$ International collaborations in postprofessional PT education could address several of the issues the profession faces toda ${ }^{26}$ while also offering a more standardized postprofessional education format that meets the objectives of both the WCPT and the professional bodies. International standards of education are already being adopted in the manual therapy and sports specialization areas. IFOMPT and The International Federation of Sports Physical Therapists have international standards for postprofessional education. ${ }^{36,37}$

Even though AUS and the USA have similar education qualifications, they demonstrate different trends in postprofessional education. Accessible opportunities for postprofessional education is of utmost importance and educators should foster programs that include hybrid learning formats or other novel distance learning formats to ameliorate the educational deserts. Incentives, such as a tiered remuneration rate and extended scope of practice with additional privileges, should be promoted for clinicians to pursue higher levels of education. Furthermore, incentives associated with increased education must correlate with growth in clinical specialists. Through collating information in this research, an international conversation between countries 
can be initiated. Postprofessional PT education can be fostered by looking and learning from our global colleagues. This collation and comparison of program offerings in the USA and AUS calls upon the profession to evaluate whether postprofessional PT education: (1) is accessible and innovative, (2) has a clearly defined pathway towards specialization for the profession and the community, (3) leads to professional privileges and compensation that are congruous with higher levels of education, and (4) meets the needs of the population.

\section{Limitations \& Additional Research}

Potential limitations of this project include the lack of historical information regarding the postprofessional educational program offerings in Australia and the lack of consistent naming of programs by educational institutions. Access to information was a main concern, but also a main reason for initiating this project. There may have been updates since the information was gathered. In light of these limitations, this research adds to the body of literature by consolidating and comparing the postprofessional education available in 2 regions of the world.

The findings from this research demonstrate the need for research on how the profession internationally can provide more tangible benefits for talented PTs pursuing postprofessional education with the goal of increasing the number of postprofessional trained PTs who can advance the profession and meet the workforce demand. Research in novel methods and models to offer postprofessional education internationally that will promote collaboration and sharing of expertise is also advocated.

\section{Conclusion}

There is a lot to learn from comparing postprofessional education in AUS and USA. The Australian PT profession's concern over the declining number of AUS PTs attending postprofessional academic program for the past decade has been validated by the declining 
number of academic postprofessional programs being offered in AUS. Postprofessional programs are on the rise in the USA. This is an imperative time to collaborate on issues related to postprofessional education. Together we can strive to address issues related to the promotion of postprofessional PT education by providing clear pathways for professional advancement with standardized terminology that lead to professional privileges and compensation that are congruous with higher levels of education. We can address the universal challenges related to access to ameliorate educational deserts through innovative program delivery. We can address the disconnect between numbers of programs offered in some areas of specialization and areas of population need, especially in geriatrics. By centralizing information, this research supports opportunities for dialogue that can guide efforts aimed at upholding postprofessional PT education. Through sharing of information and international collaboration, the physical therapy profession can strive toward advancing education and ultimately the profession. 


\section{REFERENCES}

1. World Confederation of Physical Therapy. Policy statement: Education | World Confederation for Physical Therapy. http://www.wcpt.org/policy/ps-education. Published 2011. Accessed November 18, 2015.

2. Chipchase LS, Galley P, Jull G, et al. Looking back at 100 years of physiotherapy education in Australia. Aust J Physiother. 2006;52(1):3-7. doi:10.1016/S00049514(06)70055-1.

3. Trott P, Gull G. History Australian College of Physiotherapists; 1955-2010. 2010.

4. Moffat M. A History of Physical Therapist Education Around the World. J Phys Ther Educ. 2012;26(1):13-23.

5. American Board Physical Therapy Specialists Certified Specialists Statistics. http://www.abpts.org/About/Statistics/. Accessed February 14, 2016.

6. Fazey P. The future of postgraduate clinical education. InMotion APA. September 2015:12, 13.

7. Cahalin LP, Matsuo Y, Collins SM, Matsuya A, Caro F. Educational and professional issues in physical therapy-An international study. Physiother Theory Pract. 2008;24(5):344-359. doi:10.1080/09593980802278926.

8. Carr J, Shepherd R. Clinical physiotherapy specialisation in Australia: some current views. Aust J Physiother. 1996;42(1):9-14. doi:10.1016/S0004-9514(14)60436-0.

9. About Us.

http://www.physiotherapy.asn.au/APAWCM/The_APA/About_the_APA/APAWCM/The_ APA/About_the_APA/About_Us.aspx?hkey=2d62e215-1771-4162-bced-3a94d8902af0. Accessed May 25, 2017.

10. Australian Health Practitioner Regulation Agency - Statistics. http://www.ahpra.gov.au/About-AHPRA/What-We-Do/Statistics.aspx. Accessed May 25, 2017.

11. Australian Physiotherapy Association| Specialisation. http://www.physiotherapy.asn.au/APAWCM/Careers/Career_Paths/Specialisation_Pathway /APAWCM/Careers/Career_Paths/Specialisation.aspx. Accessed May 22, 2016.

12. Australian College of Physiotherapists. http://www.physiotherapy.asn.au/APAWCM/Careers/Career_Paths/APA ACP/APAWC M/Careers/Career_Paths/ACP.aspx. Accessed June 12, 2016.

13. Australian College of Physiotherapy. http://www.physiotherapy.asn.au/APAWCM/Careers/Career_Paths/APA__ACP/APAWC M/Careers/Career_Paths/ACP.aspx?hkey=65aa82fd-e554-4e3e-b571-f2a735def272. Accessed May 25, 2017. 
14. Health Workforce Australia._Australia-Health-Workforce-Series_Physiotherapists-infocus_vF_LR.pdf. http://pandora.nla.gov.au/pan/133228/20150419-

0017/www.hwa.gov.au/sites/default/files/HWA_Australia-Health-WorkforceSeries_Physiotherapists-in-focus_vF_LR.pdf. Accessed August 28, 2016.

15. Jull, G, O’Sullivan, P. The Future for Postgraduate specialty clinical course work masters programs in Australia. Aust J Physiother. 2006;52:75-76.

16. American Board of Physical Therapy Specialties. Number of Newly Certified Specialists in Physical Therapy.

http://www.abpts.org/uploadedFiles/ABPTSorg/About_ABPTS/Statistics/CertificationbyYe ar.pdf. Published 2014. Accessed March 1, 2015.

17. Geriatrics - SpecCertMinimumCriteria.pdf.

http://www.abpts.org/uploadedFiles/ABPTSorg/Specialist_Certification/About_Certificatio n/SpecCertMinimumCriteria.pdf. Accessed May 22, 2016.

18. American Board Physical Therapy Residency Fellowship

Education_CredentialingHandbook.pdf.

http://www.abptrfe.org/uploadedFiles/ABPTRFEorg/For_Programs/Apply/ABPTRFE_Cre dentialingHandbook.pdf. Accessed July 26, 2016.

19. Mendenhall K. ABPTS Certified Specialists Statistics.

http://www.abpts.org/About/Statistics/. Accessed May 25, 2017.

20. Furze JA, Tichenor CJ, Fisher BE, Jensen GM, Rapport MJ. Physical Therapy Residency and Fellowship Education: Reflections on the Past, Present, and Future. Phys Ther. 2016;96(7):949-960. doi:10.2522/ptj.20150473.

21. Leslie Gross. Portney, Mary P. Watkins. Foundations of Clinical Research: Applications to Practice. Harlow: Pearson; 2014.

22. American Physical Therapy Association Web Template http://www.apta.org/WorkForceData/LicensedPTsByState/2015/. http://www.apta.org/WorkForceData/LicensedPTsByState/2015/. Accessed May 25, 2017.

23. Queensland Government and Council of Physiotherapy Deans Australia and New Zealand. Post Graduate Physiotherapy Programs \& Available Support for QH Physiotherapist. August 2015.

24. McNally S. Directory of Physical Therapy Residency and Fellowship Programs. http://www.abptrfe.org/DirectoryofPrograms/. Accessed February 26, 2016.

25. American Board of Physical Therapy Residency and Fellowship Education.

Residency/Fellowship Program Mentoring Resources.

http://www.abptrfe.org/ForPrograms/MentoringResourceManual/. Accessed February 24, 2016. 
26. Westervelt K, Chenette J, Merkle L, Sibold J, Crane L, Hing W. Post Professional Physical Therapist Education: A Survey from Two Different Regions of the World. Unpubl Data. 2016.

27. Centers for Disease Control and Prevention. FastStats: http://www.cdc.gov/nchs/fastats/leading-causes-of-death.htm. Accessed July 30, 2016.

28. Australian Institutes of Health and Welfare. Leading causes of death. http://aihw.gov.au/deaths/leading-causes-of-death/. Accessed July 30, 2016.

29. Jensen GM. Learning: What Matters Most. Phys Ther. 2011;91(11):1674-1689. doi:10.2522/ptj.2011.mcmillan.lecture.

30. Kulig K. Residency Education in Every Town: Is It Just So Simple? Phys Ther. 2014;94(1):151-161. doi:10.2522/ptj.2013.maley.lecture.

31. Carr J, Shepherd R. Clinical Physiotherapy Specialisation in Australia: Some current views. Aust J Physiother. 1996;42(1):9-14.

32. American Board of Physical Therapy Specialties. Certified Specialists Statistics. http://www.abpts.org/About/Statistics/. Published August 5, 2015. Accessed November 30, 2015.

33. Policy statement: Education | World Confederation for Physical Therapy. http://www.wcpt.org/policy/ps-education. Accessed November 18, 2015.

34. Lattanzi JB, Pechak CM. Educating Globally Minded Physical Therapist Students: Curriculum Strategies to Equip the Next Generation. J Phys Ther Educ. 2012;26(1):55-60.

35. Westervelt K, Ellis C, Ellis L, et al. International Collaboration in Manual Therapy: An Educational Model. J Phys Ther Educ. 2016:30(4):44-54.

36. Competencies - IFSPT. http://ifspt.org/competencies/. Accessed August 29, 2016.

37. International Federation of Orthopaedic Manipulative Physical Therapists Educational Standards IM Doc Merged.pdf. http://www.ifompt.org/site/ifompt/files/pdf/XXIFOMPT\%20Educ\%20Standards\%20\%20\% 20IM\%20Doc\%20Merged.pdf. Accessed August 29, 2016. 